OPEN ACCESS

Edited by:

Jia-bo Wang,

Fifth Medical Center of the PLA

General Hospital, China

Reviewed by:

Hui Chen,

University of Technology Sydney,

Australia

Chun Hui Zeng,

Guangxi University of Chinese

Medicine, China

${ }^{*}$ Correspondence:

Jin Wang

Wangjin0816@126.com

Qin-wan Huang

huangqinwan@cdutcm.edu.cn

${ }^{\dagger}$ These authors share first authorship

Specialty section:

This article was submitted to

Ethnopharmacology,

a section of the journal

Frontiers in Pharmacology

Received: 15 July 2020 Accepted: 03 September 2020 Published: 25 September 2020

Citation:

Zhang X-r, Li T-n, Ren Y-y, Zeng Y-j, Lv H-y, Wang J and Huang Q-w (2020)

The Important Role of Volatile

Components From a Traditional

Chinese Medicine Dayuan-Yin

Against the COVID-19 Pandemic.

Front. Pharmacol. 11:583651.

doi: 10.3389/fphar.2020.583651

\section{The Important Role of Volatile Components From a Traditional Chinese Medicine Dayuan-Yin Against the COVID-19 Pandemic}

\author{
Xiao-rui Zhang ${ }^{\dagger}$, Ting-na Li $^{\dagger}$, Yuan-yuan Ren, Yi-jia Zeng, Hong-yang Lv, Jin Wang * \\ and Qin-wan Huang *
}

College of Pharmacy, Chengdu University of Traditional Chinese Medicine, Chengdu, China

Aromatic Chinese herbs have been used to prevent plagues since ancient times. Traditional Chinese medicine has unique advantages in the prevention and treatment of epidemic diseases. According to the traditional Chinese medicine treatment plan in the National COVID-19 Diagnosis and Treatment Plan (Trial Seventh Edition) of the National Health Commission, Chinese patent medicines or prescriptions rich in aromatic Chinese herbs are selected for prevention and treatment during the period of medical observation, clinical treatment, and recovery of confirmed COVID-19 patients. Some local health committees or traditional Chinese medicine administrations recommend a variety of other ways of using traditional aromatic Chinese herbs to prevent and cure COVID-19. These involve external fumigation, use of moxibustion, and wearing of sachet. The efficacy of aromatic Chinese herbs plays a decisive role in the prevention and treatment of COVID19. The unique properties, chemical composition, and mechanism of action of aromatic Chinese herbs are worthy of extensive and in-depth experimental and clinical research. The findings are expected to provide a reference for follow-up treatment of novel coronavirus and the development of corresponding drugs. In 2003, Dayuan-Yin produced excellent results in the treatment of the SARS virus. Individually, 112 confirmed cases were administered this drug between January and April 2003, and more than $93.7 \%$ of the patients showed noticeable mitigation of the symptoms, as well as recovery. Dayuan-Yin also was selected as one of the nationally recommended prescriptions for the COVID-19. Based on the national recommendation of Dayuan-Yin prescription, this review discusses the role of volatile components in the prevention and treatment of COVID-19, and speculates the possible mechanism of action, so as to provide a basis for the prevention and treatment of COVID-19.

Keywords: COVID-19, coronavirus, volatile components, aromatic Chinese herbs, Dayuan-Yin, traditional Chinese medicine 


\section{INTRODUCTION}

When the new coronavirus infection broke out in Wuhan, China, in December 2019, WHO announced that it was PHEIC, which is named "COVID-19" (Wu et al., 2020). By mid-August 2020, more than 21,815,000 patients had been diagnosed with the disease worldwide, while 772,856 infected persons died. At present, the coronavirus has spread to 188 countries, with the US, Brazil, and India having a total of about 11,444,806 infected cases as of August 18, 2020 (Johns Hopkins University \& Medicine, J.H.U, 2020). The situation is deteriorating every day, although the number of new cases in China has declined significantly since mid-March 2020. It is known that COVID-19 is harmful to different organs of the human body. Many governments have launched a joint prevention and control plan to prevent the spread of the COVID-19 pandemic.

Despite extensive and global scientific efforts, there is little drug has had a significant clinical effect on COVID-19 (Cao B. et al., 2020). Interestingly, Traditional Chinese medicine (TCM) plays an important role in the prevention, treatment, and rehabilitation of COVID-19 (Ren et al., 2020). According to the latest data from the State Administration of traditional Chinese medicine, Dayuan-Yin, a cocktail of aromatic Chinese herbs, has a significant therapeutic effect on COVID-19 (Ruan et al., 2020). In 2003, Dayuan-Yin produced excellent results in the treatment of the SARS virus. A total of 112 confirmed cases were individually administered Dayuan-Yin between January and April 2003, with more than $93.7 \%$ of the patients showing noticeable reduction in symptoms, as well as recovery $(\mathrm{Li} \mathrm{H}$. et al., 2020). As a result of this excellent therapeutic outcome, the TCM treatment plan in the National COVID-19 Diagnosis and Treatment Plan (Trial Seventh Edition) of the National Health Commission issued by the People's Republic of China, has recommended Dayuan-Yin for normal COVID-19 patients (General Office of the National., Health Commission of the

\footnotetext{
Abbreviations: ALI, acute lung injury; CDK1, cyclin-dependent kinases 1; CDK1, cyclin-dependent kinases 1; COPD, chronic obstructive pulmonary disease; COX, cyclooxygenase; COX-2, cyclooxygenase; DPPH, 1,1-diphenyl-2-picrylhydrazyl; fMLP, $\mathrm{N}$-formyl methionyl leucyl phenylalanine; FRAP, ferric reducing antioxidant power; FRAP, ferric reducing antioxidant power; IAV, influenza A virus; IC50, 50\%inhibiting concentration; ICAM, intercellular adhesion molecule; ICAM-1, intercellular adhesion molecule; IFN, Interferon; IFN-gamma, Interferon-gamma; IL, interleukin; IL-10, interleukin-10; IL-1 $\beta$, interleukin 1 beta; IL-6, interleukin-6; iNOS, inducible nitric oxide synthase; iNOS, Nitric oxide synthase; IRF3, Interferon regulatory Factor 3; LDL, low-density lipoprotein; LTB4, Leukotriene B4; MAPKs, mitogen activated protein kinases; MCP, monocyte chemotactic protein; MIC, minimum inhibitory concentration; MUC, mucoprotein; NF- $\mathrm{B}$, nuclear factor-kappa B; NLRP3, Nucleotide-binding domain-(NOD-) like receptor protein 3; NO, nitric oxide; NP$\mathrm{SH}$, non-protein-sulthydry; Nrf2, nuclear factor erythroid 2-related factor 2; NSAIDs, nonsteroidal anti-inflammatory drugs; oxLDL, lipid peroxidation because oxidized LDLs; PGE2, prostaglandin E2; PGE2, prostaglandin E2; PHEIC, a public health emergency of international concern; RANTES, regulated upon activation normal T-cell expressed and secreted; RPMCs, Rat peritoneal mast cells; ROS, reactive oxygen species; SARS, Severe Acute Respiratory Syndrome; SFJD, Shufengjiedu Capsule; SHL, Shuanghuanglian; T3SS, type III secretion system; TBA, thiobarbituric acid; TCM, traditional Chinese medicine; TI, therapeutic index; TLR4, toll like receptor 4; TLR4, toll like receptor 4; TLR7, toll like receptor 7; TNF-alpha, tumor necrosis factor-alpha; TNF- $\alpha$, tumor necrosis factor alpha; VCAM-1, vascular cell adhesion molecule; WHO, Worldwide Health Organization.
}

people's Republic of China. et al., 2020). It has been used clinically in improving symptoms of lung condition for a long time, with the results showing that the prescription shortened the course of the disease by reducing the clinical symptoms and improving prognosis of patients. Thus, it is worthy of clinical application (Ruan et al., 2020; Wang W. et al., 2020). At present, the TCM has adopted Dayuan-Yin for the treatment of COVID19, and it has achieved good curative effect (Wang B. et al., 2020; Li D. et al., 2020). The bioactive components of Dayuan-Yin remain unknown. This is probably due to the fact that the TCM decoction has nine herbal components derived from several prescriptions in a classic TCM fashion. The complex constituents of Dayuan-Yin make it hard to carry out a detailed study on its bioactive components in a short time.

These are Atractylodes lancea (Thunb.) DC., Citrus $\times$ aurantium L., Magnolia officinalis Rehder \& E.H.Wilson, Pogostemon cablin (Blanco) Benth., Lanxangia tsao-ko (Crevost \& Lemarié) M.F.Newman \& Skornick., Ephedra sinica Stapf, Hansenia weberbaueriana (Fedde ex H.Wolff) Pimenov \& Kljuykov, Zingiber officinale Roscoe, and Areca catechu L. in Dayuan-Yin. These plants are present in Dayuan-Yin in the ratio of 15: 10: 10: 10: 6: 6: 10: 10: 10. (General Office of the National., Health Commission of the people's Republic of China. et al., 2020) (Figure 1). Eight of them are aromatic Chinese herbs.

Air pollution is a major environmental problem affecting global respiratory health (Guan et al., 2016). Moreover, aromatic Chinese herbs can be used for air disinfection (Sun and Liang, 2015). It is one of the reasons why aromatic Chinese medicine have been successfully used as key TCM for prevention of epidemics since ancient times (Luo et al., 2020). Volatile components are the main active components of aromatic Chinese herbs (Chen and Wang, 1994). It is supposed that the volatile components which are essential active ingredients in Dayuan-Yin may play a vital role in treating COVID-19 patients.

\section{BIOACTIVE VOLATILE COMPONENTS OF DAYUAN-YIN}

Most of the volatile components of Dayuan-Yin have been elucidated, and their structures are well established (Table 1). However, there are no data on volatile components extracted from Areca catechu L. Based on clinical evidence of therapeutic results with Dayuan-Yin, we summarized its potential bioactive volatile components in the treatment of COVID-19. The biological benefits of Dayuan-Yin seem to involve anti-inflammatory, antiviral, antibacterial, and immunomodulatory effects (Table 2).

\section{Anti-Viral Effect}

In autopsy studies and animal models, COVID-19 manifests mainly as acute viral pneumonia leading to respiratory failure (Chan et al., 2020; Yao et al., 2020). Antiviral drugs have been used to treat common cold, fever and influenza viruses by destroying the viral surface structure and inhibiting its entry (Hsieh et al., 2012), suggesting that antiviral drugs can be used for COVID-19. Unfortunately, no specific antiviral treatment has 


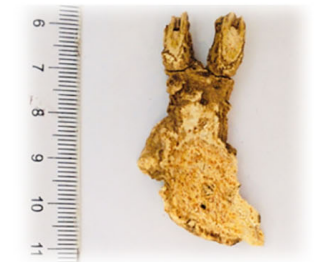

Atractylodes lancea (Thunb.) DC

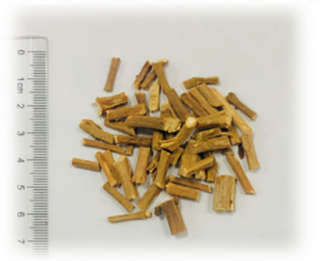

Pogostemon cablin (Blanco) Benth.

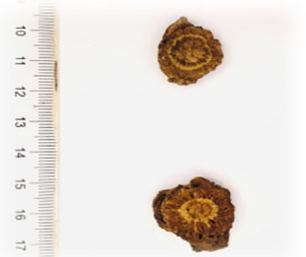

Hansenia weberbaueriana (Fedde ex H.Wolff)

Pimenov \& Kljuykov

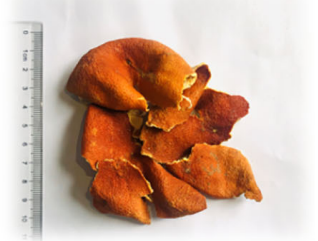

Citrus $\times$ aurantium $\mathrm{L}$.

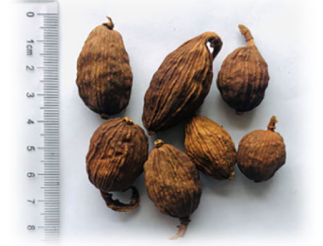

Lanxangia tsao-ko (Crevost \& Lemarié) M.F.Newman \& Skornick.

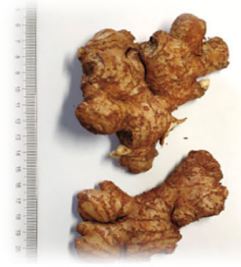

Zingiber officinale Roscoe

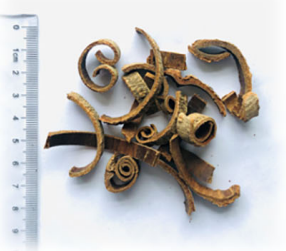

Magnolia officinalis Rehder \& E.H.Wilson

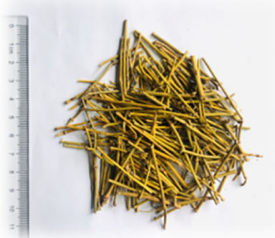

Ephedra sinica Stapf

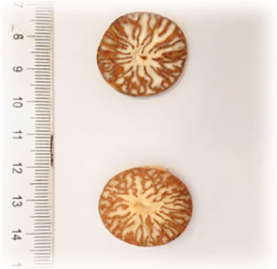

Areca catechu L.

FIGURE 1 | The processed raw materials of Dayuan-Yin in treating COVID-19.

been recommended for COVID-19 treatment because of insufficient evidence from randomized trials (Hung et al., 2020). It has been shown that many re-purposed drugs have effects against close relatives of SARS-COV-2, such as $\beta$ coronavirus, in vitro. Furthermore, lopinavir and many interferons, especially interferon beta, have moderate effects against SARS-COV in vitro and can be used in combination with ribavirin (Chen et al., 2004; Chan et al., 2013). Administration of antiviral drugs soon after symptoms appear reduces the release of virus in respiratory secretions of patients with COVID-19, thereby decreasing their infectivity to others. Targeted preventive treatment for contacts reduces their risk of infection (Welliver et al., 2001; Oriol and Bonaventura, 2020).

Patchouli oil is extracted from Pogostemon cablin (Blanco) Benth. Some studies in vitro have shown that patchouli oil exerted anti-viral effects against Coxsackie virus $\left(\mathrm{IC}_{50}=0.081 \mathrm{mg} /\right.$ $\mathrm{ml}$, TI 1.25), adenovirus( $\mathrm{IC}_{50}=0.084 \mathrm{mg} / \mathrm{ml}$, TI 1.20), influenza A virus $\left(\mathrm{IC}_{50}=0.088 \mathrm{mg} / \mathrm{ml}\right.$, TI 1.15), and respiratory syncytial virus $\left(\mathrm{IC}_{50}=0.092 \mathrm{mg} / \mathrm{ml}\right.$, TI 1.10) (Wei et al., 2012). Evaluation of the antiviral properties of six chemical compositions of Atractylodes lancea (Thunb.) D DPPH.C. revealed that atractylodin produced the most significant effect at doses of $10-40 \mathrm{mg} / \mathrm{kg}$ for five days, and attenuated IAV-induced pulmonary injury via regulation of the TLR7 signaling pathway (Cheng et al., 2016). Moreover, 1,8-cineole, the major constituent of the essential oil of Lanxangia tsao-ko
(Crevost \& Lemarié) M.F.Newman \& Skornick., is commonly applied for treating inflammatory diseases of the respiratory tract caused by viruses since it potentiates the antiviral effect of IRF3, in addition to its inhibitory effect on proinflammatory NF- $\mathrm{BB}$ signaling (Müller et al., 2016).

\section{Anti-Inflammatory Effect}

The levels of proinflammatory factors i.e. IL-2, IL-7, IL-10, GCSF, IP10, MCP1, mip1a, and TNF - $\alpha$ in the plasma of critically-ill patients were higher than those in plasma of patients who were not in intensive care, suggesting that "cytokine storm" is closely related to the severity of COVID-19 (Huang et al., 2020). Cytokinestorm is a very prominent pathophysiological feature of COVID-19 infection (Lin et al., 2020). Extensive endothelial barrier disruption and uncontrolled cytokine storm promote uncontrolled inflammatory response which is the basis of the core mechanism underlying acute respiratory distress syndrome (ARDS) (Huang et al., 2017), although this phenotype varies among individuals. Experimental models of acute lung injury (ALI) and human genome-wide association studies of ARDS indicate that cytokine storm plays an essential role in the pathophysiology of ARDS ( Biondi et al., 1986; Huang et al., 2017). Moreover, the most common and severe complication of COVID-19 is ARDS (Huang et al., 2017). Therefore, an understanding of the cytokine storm that aggravates ARDS in COVID-19 may lead to early and effective intervention in 
TABLE 1 | Name of volatile oil in Dayuanyin prescription.

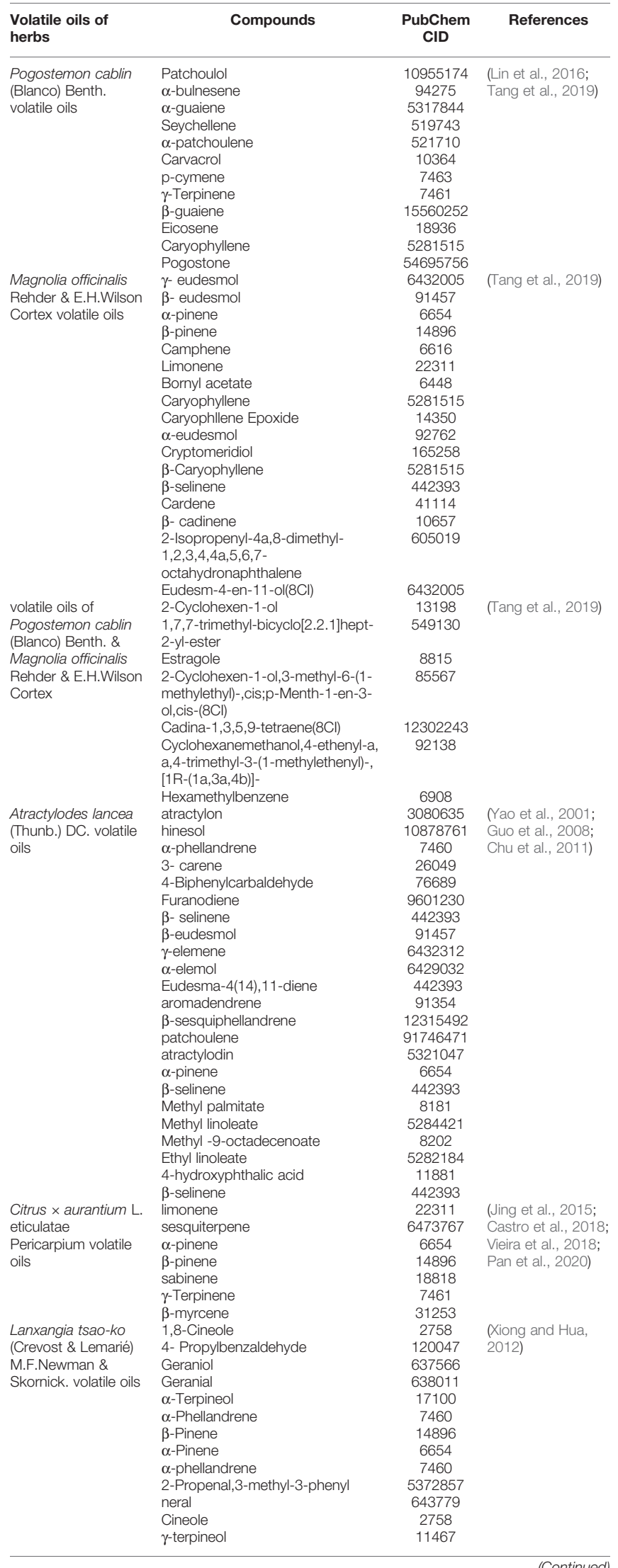

TABLE 1 | Continued

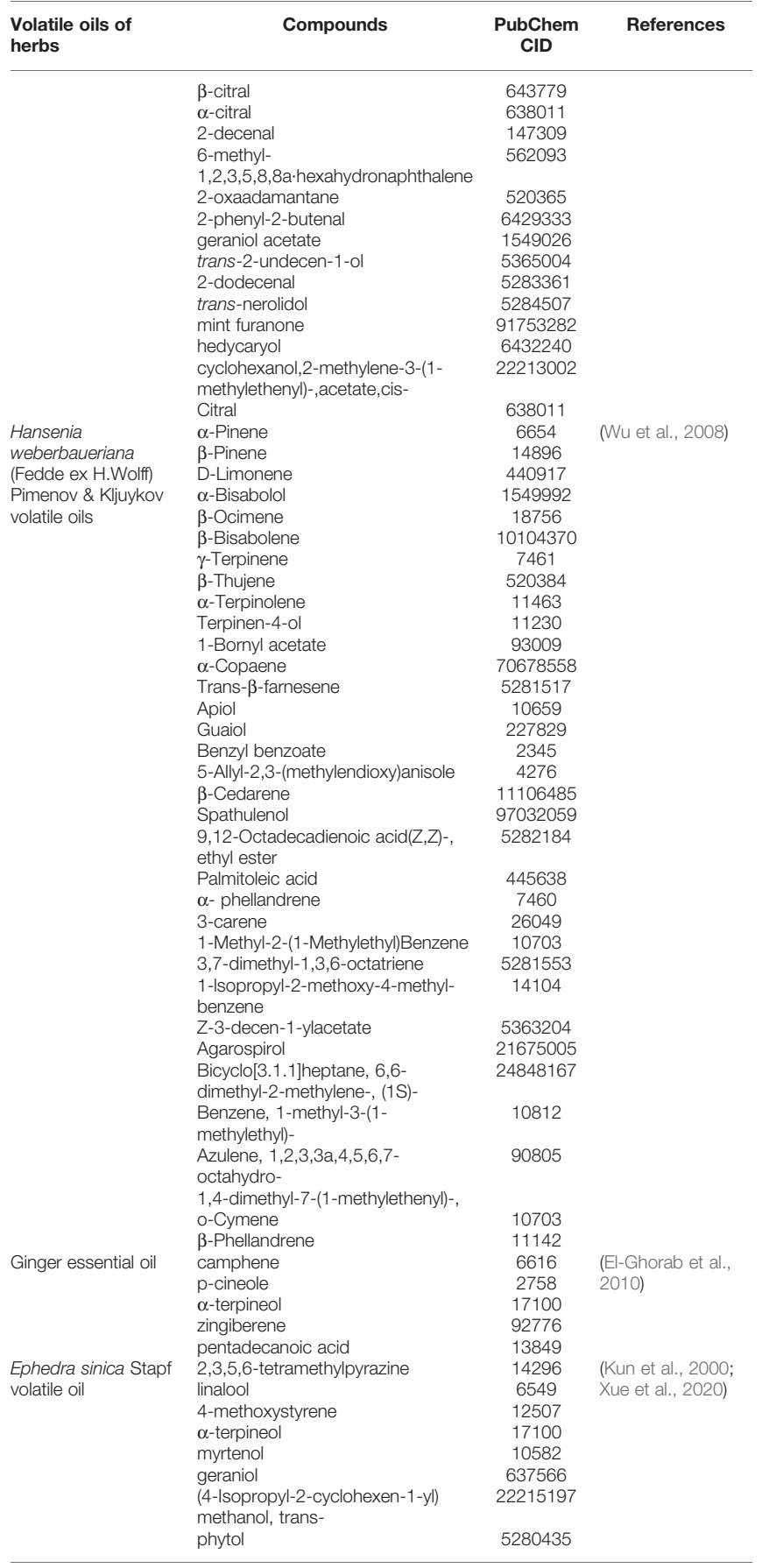

critically-ill COVID-19 patients. It seems necessary to directly inhibit inflammatory response in the lungs because cytokine storm can be alleviated with inflammatory therapy (Cao P. et al., 2020). Previous studies have shown the benefits of antiinflammatory drugs in lung disease: they slow down impairment of lung function, reverse the inflammatory parameters nearly back to normal values, and improve patients' survival (Konstan et al., 2011; Lubamba et al., 2011). Ibuprofen, a popular antiinflammatory drug, is recommended for airway inflammation in cystic fibrotic lung disease (Flume et al., 2007). Studies have shown 
TABLE 2 | The mechanism of action of volatile components in Dayuanyin prescription.

Bioactivities Volatile oils of herbs Mechanisms

\begin{tabular}{ll}
\hline Anti-inflammatory & Pogostemon cablin (Blanco) Benth. \\
activity & volatile oils
\end{tabular}

Magnolia officinalis Rehder \& E.H.Wilson Cortex volatile oils Atractylodes lancea (Thunb.) DC. volatile oils

Citrus $\times$ aurantium L. Pericarpium volatile oils Lanxangia tsao-ko (Crevost \& Lemarié) M.F.Newman \& Skornick. volatile oils

Hansenia weberbaueriana (Fedde ex H.Wolff) Pimenov \& Kljuykov volatile oils

Ginger volatile oil

Antiviral activity

Anti-oxidative activity

Lanxangia tsao-ko (Crevost \&

Lemarié) M.F.Newman \& Skornick. volatile oils

Magnolia officinalis Rehder \&

E.H.Wilson Cortex volatile oils
Patchoulene: cyclin $E \downarrow$, cyclin $B \downarrow$, CDK1 $\downarrow$; the subsequent S-phase

Atractylodes lancea (Thunb.) DC.

volatile oils

Citrus $\times$ aurantium L. Pericarpium volatile oils arrest, IFN-gamma $\downarrow$, IL-10 $\downarrow$


$\mathrm{NP}-\mathrm{SH} \uparrow$

Patchoulene: regulates on the balance between Nrf2 and NF- $\mathrm{kB}$ p65 signaling pathways

Patchoulene: vitro neutrophil fMLP chemotaxis $\downarrow$, phagocytic activity $\uparrow$; ear edema $\uparrow$, myeloperoxidase (MPO) activity $\uparrow$

Patchoulene: NF- $\kappa \mathrm{B} \downarrow$, Nrf2 $\uparrow, \mathrm{miR}-146 \mathrm{a}$ expression $\uparrow$

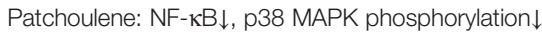

Patchoulene: regulates on the balance between Keap1-Nrf2 and NF- $\kappa B$ signaling pathways

Magnolia officinalis Rehder \& E.H.Wilson Cortex volatile oils: PGE2/TNF-

$\alpha \downarrow, \| L-1 \beta \downarrow$

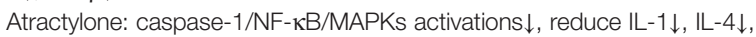

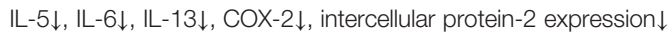

Atractylone: RPMCs degranulation intracellular Ca2+ level ([Ca2+]) $\downarrow$,

tryptase $\downarrow$, histamine $\downarrow$ p56lck tyrosine kinase activity $\downarrow$; histidine

decarboxylase activity and expression $\downarrow$, tryptase and histamine

releases $\downarrow$ in $\mathrm{PMACl}$-induced $\mathrm{HMC}-1$ cells; morphological alteration and

flamentous actin formation in stem cell factor-stimulated RPMCs animal

model

Atractylone: NLRP3 inflammasome $\downarrow$, TLR4 activation $\downarrow$

Hinesol: $\mathrm{H}^{+}, \mathrm{K}^{+}$-ATPase activity $\downarrow$

Limonene: TNF- $\alpha \downarrow$, neutrophils chemotaxis $\downarrow$, leukocytes chemotaxis $\downarrow$

Limonene: iNOS $\downarrow$, COX $\downarrow$, PGE2 $\downarrow$; TNF- $\alpha \downarrow$, IL-1 $1 \downarrow$, and IL-6 $\downarrow$;

Citrus $\times$ aurantium L. Pericarpium volatile oils: Nitric oxide $\downarrow$, iNOS $\downarrow$, COX-

$2 \downarrow$

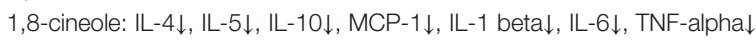

IFN-gamma $\downarrow$, NF-kB p65 $\downarrow$, ICAM-1 $\downarrow$; VCAM- $1 \downarrow$ in lung tissues of mice

infected with influenza $A$ virus.

1,8-cineole: mucin-filled goblet cells $\downarrow$, MUC2 $\downarrow$, MUC19 $\downarrow$, NF-kappa B-

activity $\downarrow$

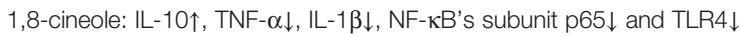

1.8-cineole: LTB4 $\downarrow$ and PGE2 $\downarrow$ in human blood monocytes ex vivo in the treatment of bronchial asthma.

1.8-cineole: TNF $\alpha \mathrm{C}, \mathrm{IL}-1 \beta \downarrow$, leukotriene $\mathrm{B} 4 \downarrow$, thromboxane $\mathrm{B} 2 \downarrow$ in human blood monocytes in vitro

Hansenia weberbaueriana (Fedde ex H.Wolff) Pimenov \& Kljuykov volatile oils: NO $\downarrow$ in RAW 264.7 cells.

$\alpha$-pinene: MAPKs $\downarrow, N F-\kappa B \downarrow$ in mouse peritoneal macrophages

$\alpha$-pinene: LPS-induced nuclear translocation of NF- $\kappa \mathrm{B} \downarrow$ in TPS- 1 cells by $\kappa \mathrm{B} \alpha$ expression $\uparrow$ in a dose-dependent manner

PLS-induced IL-8 secretion $\downarrow$, RANTES $\downarrow$ in human bronchial epithelial cells (BEAS-2B)

anti-Coxsackie virus (IC50 $0.081 \mathrm{mg} / \mathrm{ml}, \mathrm{TI} 1.25)$, anti-adenovirus (IC50

0.084 mg/ml, TI 1.20), anti-influenza A virus (IC50 0.088 mg/ml, TI 1.15), and anti-respiratory syncytial virus (IC50 $0.092 \mathrm{mg} / \mathrm{ml}, \mathrm{TI} 1.10$ )

Regulate the TLR7 signaling pathway.

1,8-cineole: IRF3 antiviral activity $\uparrow$, proinflammatory NF- $\kappa$ B signalling $\downarrow$

(Su et al., 2015)

(Chen et al., 2015)

(Yang et al., 2018)

(Silva-Filho et al., 2016)

(Chen et al., 2017)

(Li et al., 2014)

(Sun et al., 2016)

(Cao et al., 2015)

(Kim et al., 2016)

(Han et al., 2016)

(Tang et al., 2018)

(Kanako et al., 2000)

(Vieira et al., 2018)

(Yoon et al., 2010)

(Dang et al., 2020)

(Li et al., 2016)

(Sudhoff et al., 2015)

(Zhao et al., 2014)

(Juergens et al., 1998b)

(Juergens et al., 1998b)

(Bi et al., 2018)

(Kim et al., 2015)

(Zhou et al., 2004)

(Podlogar and Verspohl, 2012)

(Wei et al., 2012)

(Cheng et al., 2016)

(Müller et al., 2016)

Scavenging DPPH free radicals, providing hydrogen atoms, scavenging superoxide free radicals

Scavenge DPPH- radical activity with an IC50 of $288.7 \mu \mathrm{g} / \mathrm{mL}$, lipid peroxidation $\downarrow$, and effects on T-AOC in the serum and organ tissues of mice

Citrus reticulata peel oil prevented LDL lipid peroxidation because oxLDL are absorbed by the macrophages' scavenger molecules, forming foam cells

Certain monoterpenes and essential oils: LDL oxidation $\downarrow$
(Guo, 2012)

(He et al., 2020)

(Yoon et al., 2010; Castro et al., 2020)

(Barter, 2005)

(Naderi. et al., 2004)

(Continued) 
TABLE 2 | Continued

\begin{tabular}{|c|c|c|c|}
\hline Bioactivities & Volatile oils of herbs & Mechanisms & References \\
\hline & & $\begin{array}{l}\text { Limonene: protect the lens epithelial cells from oxidative stress through } \\
\text { antioxidant and anti-apoptotic pathways. }\end{array}$ & \\
\hline & & $\begin{array}{l}\text { Limonene: be able to attenuate the oxidative stress impairment on in vitro } \\
\text { and in vivo models }\end{array}$ & (Ahmad and Beg, 2013) \\
\hline & Lanxangia tsao-ko (Crevost \& & Weak in scavenge DPPH- radical activity, TBA, and FRAP & (Yang et al., 2010) \\
\hline & $\begin{array}{l}\text { Lemarié) M.F.Newman \& Skornick. } \\
\text { volatile oils }\end{array}$ & $\begin{array}{l}\text { 1,8-cineole: reactive oxygen species } \downarrow \text {, superoxide dismutase } \downarrow \text {, catalase } \downarrow \text {, } \\
\text { malondialdehyde } \downarrow\end{array}$ & (Kennedy-Feitosa et al., 2016) \\
\hline \multirow[t]{9}{*}{$\begin{array}{l}\text { Anti-bacterial } \\
\text { activity }\end{array}$} & $\begin{array}{l}\text { Pogostemon cablin (Blanco) Benth. } \\
\text { volatile oils }\end{array}$ & 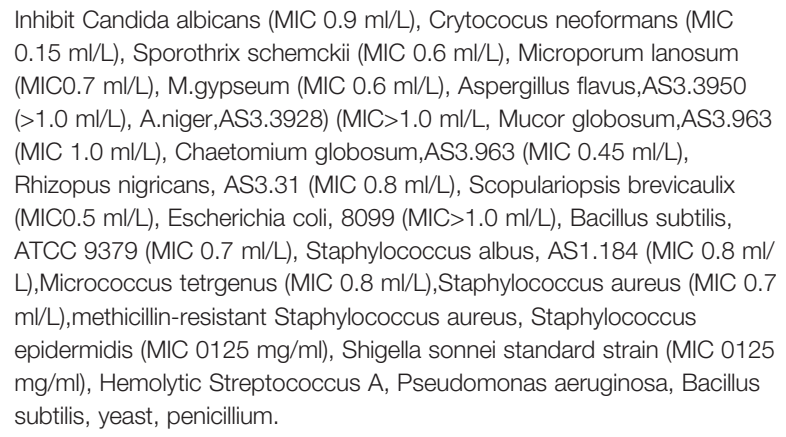 & $\begin{array}{l}\text { (Zhou et al., 2014; Lin et al., } \\
\text { 2016; Wang et al., 2018) }\end{array}$ \\
\hline & $\begin{array}{l}\text { Magnolia officinalis Rehder \& } \\
\text { E.H.Wilson Cortex volatile oils }\end{array}$ & $\begin{array}{l}\text { Inhibit Staphylococcus aureus, Candida albicans, methicillin-resistant } \\
\text { Staphylococcus aureus, Staphylococcus epidermidis, Enterococcus } \\
\text { faecalis, Shigella sonnei, Escherichia coli, Listeria monocytogenes, } \\
\text { Salmonella, Bacillus cereus, Pseudomonas aeruginosa. }\end{array}$ & (Guo, 2012; Tang et al., 2019) \\
\hline & $\begin{array}{l}\text { Atractylodes lancea (Thunb.) DC. } \\
\text { volatile oils }\end{array}$ & $\begin{array}{l}\text { Inhibit Gram-positive and Gram-negative bacteria due to disruption of the } \\
\text { cell membrane. }\end{array}$ & (He et al., 2020) \\
\hline & & $\begin{array}{l}\beta \text {-eudesmol has two-way regulation of gastrointestinal motility, which } \\
\text { may be anticholinergic or directly acting on gastrointestinal smooth } \\
\text { muscle. }\end{array}$ & (Wang et al., 2002) \\
\hline & & Hinesol: $\mathrm{H}^{+}, \mathrm{K}^{+}$-ATPase activity $\downarrow$ & (Kanako et al., 2000) \\
\hline & $\begin{array}{l}\text { Citrus } \times \text { aurantium } L \text {. Pericarpium } \\
\text { volatile oils }\end{array}$ & Inhibit the phytopathogenic fungus Sclerotinia sclerotiorum. & (Dias et al., 2020) \\
\hline & $\begin{array}{l}\text { Lanxangia tsao-ko (Crevost \& } \\
\text { Lemarié) M.F.Newman \& Skornick. }\end{array}$ & $\begin{array}{l}\text { Protect the mice from Staphylococcus aureus or Escherichia coli } \\
\text { infection. }\end{array}$ & (Dai et al., 2016) \\
\hline & volatile oils & 1,8-cineole: inhibits S. aureus, Escherichia coli, Moraxella catarrhalis. & (Schürmann et al., 2019) \\
\hline & Ginger volatile oil & $\begin{array}{l}\text { Inhibit Pseudomonas aeroginosa bacteria, S. typhimurium and S. flexneri, } \\
\text { Gram-negative bacteria, slightly. }\end{array}$ & (Mesomo et al., 2013) \\
\hline \multirow[t]{4}{*}{ Other aspects } & $\begin{array}{l}\text { Lanxangia tsao-ko (Crevost \& } \\
\text { Lemarié) M.F.Newman \& Skornick. } \\
\text { extract }\end{array}$ & $\begin{array}{l}\text { Epicatechin has anti-inflammatory properties, quercetin has the strongest } \\
\text { neuroprotective effect of PC-12 cells induced by } \mathrm{H}_{2} \mathrm{O}_{2} \text {, and DPPH } \\
\text { radical-scavenging activity. }\end{array}$ & (Zhang et al., 2014) \\
\hline & Hansenia weberbaueriana (Fedde ex & Inactivate the influenza virus A/FM/1/47 directly and reduce the titer. & (Guo et al., 2005) \\
\hline & H.Wolff) Pimenov \& Kljuykov extract & $\begin{array}{l}\text { Falcarindiol inhibited DC maturation by blocking the canonical pathway of } \\
\text { nuclear factor-kappaB and phosphorylated p38. }\end{array}$ & (Mitsui et al., 2010) \\
\hline & & $\begin{array}{l}\text { Falcarindiol inhibit Pseudomonas aeruginosa by repressing virulence- } \\
\text { related genes, including the T3SS; quorum sensing synthase genes lasIR } \\
\text { and rhllR; lasB; motility-related genes fliC and fliG; and phenazine } \\
\text { synthesis genes phzA1 and phzA2. }\end{array}$ & (Zhang et al., 2020) \\
\hline
\end{tabular}

that long-term prediagnostic use of nonaspirin NSAIDs (e.g., ibuprofen) is associated with a significant reduction in lung cancer survival (Brasky et al., 2012). In addition, barictinib, fedratinib, and ruxolitinib are active and selective JAK inhibitors which have been approved for rheumatoid arthritis and myelofibrosis. All three drugs are effective anti-inflammatory agents, and as JAK-STAT signaling inhibitors, they may be effective against the consequences of elevated levels of cytokines (including interferon- $\gamma$ ) usually observed in patients with COVID-19 (Stebbing et al., 2020). The UK is currently conducting a randomized evaluation of COVID19 treatment (recovery) trial, based on the announcement on June 16, 2020 , that dexamethasone had been shown to significantly improve the prognosis of COVID-19 patients receiving respiratory support
(Recovery, Randomised Evaluation of COVid-19 therapy trial, 2020). Dexamethasone is a glucocorticoid which can be used as a synthetic form of the natural hormone cortisol (Cain and Cidlowski, 2017). It has the same anti-inflammatory effect as cortisol. It inhibits the release of inflammatory chemokines by immune cells, thereby improving the prognosis of patients by reducing the severity of ARDS (Lester et al., 2020). In European patients, low-dose dexamethasone reduces mortality by $33 \%$ in critically patients requiring invasive ventilation (Lim et al., 2020). However, the implementation of appropriate dexamethasone use in low-and-middle-income countries has been a challenge. For example, corticosteroids may cause sepsis in some prevalent parasitic infections in Africa (Nutman, 2020). Therefore, the use of dexamethasone in African patients who have not been 
diagnosed with COVID-19 may lead to unexpected consequences (Brotherton et al., 2020). During the treatment of COVID-19, DayuanYin also reduces the severity of ARDS by inhibiting the release of inflammatory chemokines from immune cells. As a classic prescription in ancient China, Dayuan-Yin can play a safe and effective role in the treatment of respiratory infections in a more adverse environment. Thus, it can avoid such problems in a large extent.

Anti-inflammatory property is widespread in various sources of volatile components. Several data have found that 1,8-cineole significantly improved lung function and health conditions, and reduced dyspnea in patients with asthma, acute bronchus, and chronic obstructive pulmonary disease (COPD). Moreover, it significantly reduced the frequency of cough in patients with acute bronchitis, and alleviated frequent exacerbations in patients with COPD and frequent exacerbations, notably (Worth et al., 2009; Worth and Dethlefsen, 2012; Fischer and Dethlefsen, 2013; Vogelmeier et al., 2018). In a mouse model of LPS-induced acute pulmonary inflammation, 1,8-cineole upregulated IL-10 in lung tissues, and decreased the expressions of TNF- $\alpha$, IL-1 $\beta$, NF- $\kappa B$ 's subunit p65 and TLR4 (Zhao et al., 2014). Moreover, 1,8-cineole was shown to inhibit LTB4 and PGE2 (pathways of AA-metabolism in human blood monocytes) in bronchial asthma in vitro (Juergens et al., 1998b). In addition, 1,8-cineole decreased levels of TNF $\alpha$, IL$1 \beta$, leukotriene $\mathrm{B} 4$, and thromboxane B2 in human blood monocytes in vitro (Juergens et al., 1998a).

Pogostone, a bioactive component extracted from Pogostemon cablin (Blanco) Benth., reduced the total population of T cells under ConA stimulation by blocking $\mathrm{T}$ cell proliferation via downregulation of cyclin E, cyclin B, and CDK1. Subsequent S-phase arrest inhibited the production of IFN-gamma and IL-10 (Su et al., 2015). Simultaneously, pogostone pretreatment mitigated ethanolinduced gastric ulcer in rats by downregulation of IL-6 and TNFalpha, and upregulation of IL-10 and non-protein-sulfhydryl (NP$\mathrm{SH}$ ) groups in the gastric mucosa (Chen et al., 2015). In lung disease, pogostone exerted potent protective effects against lipopolysaccharide-induced acute lung injury in mice by decreasing TNF- $\alpha$-induced cell injury in A549 cells through modulation of the balance between Nrf2 and NF- $\mathrm{BB}-\mathrm{p} 65$ signaling pathways (Yang et al., 2018). Pogostone significantly inhibited the protein and mRNA expressions of proinflammatory mediators such as TNF- $\alpha$, IL-6, IL-1 $\beta$, NO, and PGE2. Pogostone also significantly reduced LPS-induced mortality in mice, suppressed the production of proinflammatory mediators in serum. And it attenuated liver and lung injury via downregulation of the mRNA expressions of inflammatory mediators in multiple organs due to inhibition of activation of $\mathrm{NF}-\kappa \mathrm{B}$ and phosphorylation of p38 MAPK (Li et al., 2014). Pre-treatment with pogostone markedly mitigated LPS-induced acute lung injury in mice, improved survival, attenuated histological alterations in the lungs, reduced MPO and MDA levels, decreased the wet/dry weight ratio of lungs, and down-regulated proinflammatory mediators, such as TNF-a, IL-1 beta and IL-6. Furthermore, pretreatment with pogostone enhanced the Nrf2dependent genes NQO-1, GCLC, and HO-1, but suppressed the NF-kappa B regulated genes TNF-alpha, IL-1 beta, and IL-6. The mechanism involved in the protective effect of pogostone was correlated with its regulation of the balance between Keap1-Nrf2 and NF-kappa B signaling pathways (Sun et al., 2016). Moreover, volatile oils from Pogostemon cablin contain a bioactive component named $\beta$-patchoulene which has been shown to significantly decrease mortality and lung wet/dry weight ratio of mice, and mitigate pathological changes in lungs, when compared to model group. It suppressed LPS-induced activation of NF-kappa B, and markedly upregulated Nrf2 and miR-146a (Chen et al., 2017).

\section{Anti-Oxidative Properties}

Oxidative stress and inflammation form a positive feedback cycle (Mittal et al., 2014). In lung disease, excessive inflammation and oxidative stress lead to adverse outcomes. For instance, patients with COPD are usually affected by other diseases (Rabe and Watz, 2017). Several mechanisms in lung inflammation and oxidative stress destroy DNA and lead to an imbalance between tissue repair and cell proliferation, which seems to promote the link between COPD and lung cancer (Wilson et al., 2008; Houghton, 2013; Durham and Adcock, 2015). Under normal conditions, the production and elimination of ROS maintain a crucial balance between oxidation and antioxidation (Cao et al., 2019). In such a balance, the signal pathways are regulated, and cell proliferation can be guaranteed. When inflammatory factors destroy this balance, oxidative stress enhances the maturation of proinflammatory factors, leading to oxidative damage to cells and multisystem diseases (Sies, 2015; Kruk et al., 2019). Antioxidant drugs have been used in lung diseases. For example, antioxidants have been recommended for reduction of mortality or prevention of organ damage in animal models of acute lung injury induced by lipophilic acids (Hsu et al., 2006; Zhu et al., 2020). Vitamin $\mathrm{C}$ has also been shown to reduce the incidence of pneumonia in several controlled trials for human subjects (Hemila, 2017).

The essential oil of Magnolia officinalis Rehder \& E.H. Wilson exerts antioxidant effect by scavenging 1,1-diphenyl-2picrylhydrazyl (DPPH) radical and superoxide anion radical. The essential oil contains $\beta$-eucalyptol with a hydroxyl group which can provide hydrogen atom for scavenging DPPH radical. Moreover, with increase in volatile oil concentration, the antioxidant capacity gradually increased (Guo, 2012). The essential oil from Atractylodes lancea (Thunb.) DC. showed a strong antioxidant effect in vitro and indicated by $\mathrm{DPPH}$-radical scavenging property, with an $\mathrm{IC}_{50}$ of $288.7 \mu \mathrm{g} / \mathrm{ml}$. Moreover, it inhibited lipid peroxidation, and affected total antioxidant capacity (T-AOC) in the serum and organ tissues of mice (He et al., 2020). In short-term cigarette smoke (CS)induced acute lung inflammation, 1,8-cineole decreased oxidative stress involving reactive oxygen species, by increasing superoxide dismutase and catalase, while reducing levels of malondialdehyde, inflammation, and the NF-kappa B p65 subunit (Kennedy-Feitosa et al., 2016).

\section{Antibacterial Properties}

The major components of Pogostemon cablin (Blanco) Benth. are carvacrol (47.5\%) and p-cymene (15.2\%). It completely inhibits the growth of E. coli at a level of $0.05 \%$ (Lin et al., 2016). The essential oil of Atractylodes lancea (Thunb.) DC. exhibited antibacterial effects against Gram-positive and Gram-negative bacteria due to the cell membrane (He et al., 2020). In chronic 
rhinosinusitis, 1,8-cineole suppressed the growth of $S$. aureus, Escherichia coli, Moraxella catarrhalis due to downregulation of significant and critical players in biofilm generation (Agra, Sara, and $\sigma^{\mathrm{B}}$ ) (Schürmann et al., 2019). On the other hand, the major constituent of the essential oil of Atractylodes lancea (Thunb.) DC. is $\beta$-eudesmol. In terms of intestinal flora, $\beta$-eudesmol has two-way regulation for gastrointestinal motility: anticholinergic pathway and direct effect on gastrointestinal smooth muscle.

Antibacterial effect is an essential pharmacological property of volatile compounds (Houdkova et al., 2017; Riad et al., 2020). Secondary bacterial co-infection is common in patients with COVID-19 infection, and it leads to adverse prognosis (Macintyre et al., 2018). At present, many antibiotics have been used in the treatment of COVID-19. For example, Shufeng Jiedu Capsule (SFJD) prevents acute upper respiratory tract infection and positively affects fever, cough, and headache. Studies have shown that SFJD significantly reduced the levels of serum PGE2, IL-1 $\beta$, and TNF- $\alpha$ in rats with acute pharyngitis (Qian, 2019). Being a popular antiviral and antibacterial drug, SFJD is one of the drugs for COVID-19 treatment in China (Pan X. et al., 2020). In addition, Shuanghuanglian (SHL) is a popular anti-bacterial drug. It has various pharmacological potential such as antibacterial, antiviral, and immune-enhancing properties which can be exploited in the treatment of acute upper respiratory tract infection (Zhang et al., 2013). Preliminary studies in vitro showed that SHL oral liquid inhibited SARS-COV-2. Indeed, SHL has been used to carry out clinical research on COVID-19 in Shanghai Public Health Clinical Center and Tongji Hospital Affiliated to Huazhong University of Science and Technology (Pan X. et al., 2020).

The antibacterial effects of volatile components of Dayuan-Yin are not limited to upper respiratory tract infections: these volatile components also regulate intestinal flora, treat gastric ulcers, and improve gastrointestinal symptoms. Human gut microbes are the "second genome" of the human body (Backhed et al., 2005; Gill et al., 2006; Cani and Delzenne, 2007). The composition of intestinal flora is closely related to human health status, and it plays an essential role in maintaining physiological balance (Schuijt et al., 2016). It has been confirmed that intestinal flora reduces ventilatorassociated pneumonia and enteritis by enhancing the function of primary alveolar macrophages (Bradley et al., 2019). Patients with COVID-19 showed intestinal microbial malnutrition and decreased microbial flora levels of some probiotics such as Lactobacillus and Bifidobacterium. The latest version of novel coronavirus pneumonia diagnosis and treatment plan released by the People's Republic of China National Health Council suggests that intestinal microbiota should be used in severe and critical cases to maintain intestinal micro ecological balance (General Office of the National., Health Commission of the people's Republic of China. et al., 2020).

\section{EFFECTS OF NON-VOLATILE COMPONENTS}

Apart from the biological effects of the volatile components mentioned above, other non-volatile components of DayuanYin also have abundant pharmacological properties.
Epicatechin, one of the chemical components of Lanxangia tsaoko (Crevost \& Lemarié) M.F.Newman \& Skornick., exhibited excellent anti-inflammatory properties in LPS-stimulated macrophage RAW 264.7 cells. Quercetin, one of the chemical components of Lanxangia tsao-ko (Crevost \& Lemarié) M.F. Newman \& Skornick., produced the most potent neuroprotective effect on PC-12 cells induced via $\mathrm{H}_{2} \mathrm{O}_{2}$ and $\mathrm{DPPH}$ radicalscavenging properties (Zhang T. T. et al., 2014). It was shown that SFE- $\mathrm{CO}_{2}$ extract of Hansenia weberbaueriana (Fedde ex H.Wolff) Pimenov \& Kljuykov significantly prolonged average survival time of mice with influenza virus pneumonia, directly killed the influenza virus, and reduced the hemagglutination titer. Hansenia weberbaueriana (Fedde ex H.Wolff) Pimenov \& Kljuykov induced immunosuppressive effects in vitro. Falcarindiol, the main bioactive compound in Hansenia weberbaueriana (Fedde ex H.Wolff) Pimenov \& Kljuykov, inhibited DC maturation by blocking the canonical pathway of nuclear factor-kappaB and phosphorylated p38 (Mitsui et al., 2010). Falcarindiol inhibited the growth of Pseudomonas aeruginosa by repressing virulencerelated genes, including the T3SS; quorum sensing synthase genes lasIR and rhlIR; lasB; motility-related genes fliC and fliG; and phenazine synthesis genes phzA1 and phzA2 (Zhang et al., 2020).

It is obvious that Dayuan-Yin exerts extensive biological properties such as antiviral, anti-inflammatory, antioxidative, and antibacterial effects. It can be inferred that Dayuan-Yin may play an essential role in preventing COVID-19 pandemic.

\section{SUMMARY AND FUTURE PROSPECTS}

At present, there are no conventional drugs that can cure COVID-19 (Cao B. et al., 2020). However, according to data collected by the National Health Commission of the people's Republic of China, clinical practice in Chinese hospitals have reported that traditional Chinese medicine has a definite therapeutic effect in the early stages of COVID-19 infection (Liu C.-X. et al., 2020). As a significant part of medical practice, Chinese medicine has been used to treat human diseases for more than 5,000 years ( $\mathrm{Li}$ and Kan, 2017). In recent decades, volatile compounds extracted from medicinal plants have attracted more and more attention due to their important biological effects such as antiviral, anti-inflammatory, and antibacterial properties. Besides, they are non-toxic and have few side effects, making them suitable for use as drugs. This review discussed the potential role of traditional Chinese medicine in terms of volatile components. The antiinflammatory, antiviral, antibacterial and immunomodulatory effects of these volatiles seem to play the most critical roles in treating patients infected with COVID-19. However, there are still lack of clinical trials on Dayuan-Yin. These need to be done in future.

In China, the situation of COVID-19 pandemic prevention and control has improved. The national pandemic situation has been controlled. However, with the resumption of factory work, re-opening of shopping malls, and resumption of transportation, the cross-flow of personnel has increased significantly, and the 
probability of close contact between people has increased tremendously too. In particular, with likelihood of increase in imported cases from abroad, the epidemic prevention and control should not be relaxed. It is essential to improve the ability of the human body to withstand infection. In addition to frequent washing of hands, wearing masks, social distancing and other measures, the "Chinese medicine sachet" can be used as an essential means of prevention. This stems from a very important theory of traditional Chinese medicine, namely "treating predisease". This idea in traditional Chinese medicine originated in the Yin and Shang Dynasties, took shape in Zhouyi, and formed in Huangdi Neijing (Xu et al., 2016). Chinese doctors in the past dynasties attached great importance to the prevention and treatment of diseases. They emphasized the prevention of diseases first, especially infectious diseases (Lian et al., 2020). Wearing Chinese medicine sachet is another special treatment of "treating pre-disease" (Chen et al., 2020). Chinese medicine sachet has been used to prevent disease since ancient times. In this method, aromatic Chinese medicine is put into a unique bag and worn on the chest to prevent respiratory diseases. This is known as "Xiangpei therapy" (Zhang Q. et al., 2014). From the perspective of modern medicine, the medicinal fragrance (i.e., volatile oil components) of Chinese medicine sachet stimulates the nasal mucosa, promotes the secretion of immunoglobulins, and kills all kinds of viruses at the same time, thereby playing multiple roles in regulating immune function, and exerting antibacterial and anti-viral effects (Lvy and Bai, 2017). Interestingly, early intervention with aromatic Chinese medicine blocks the course of diseases and relieves symptoms in clinical practice through oral administration, external fumigation, and moxibustion (Lun and Chen, 1987; Chen et al., 2013). Aromatic Chinese medicine dispels exterior pathogenic factors, regulates $q i$, activates blood circulation, breaks blood stasis, and disperses nodules. The application of aromatic Chinese medicine embodies the theory of "internal disease and external treatment" of traditional Chinese medicine (Hu et al., 2010). Since the outbreak of COVID-19, fumigation has been used for air disinfection to prevent the spread of the virus. In the clinical treatment period, the application of moxibustion plays the role of anti-inflammatory agent, regulates immune function, and prevents deterioration of the patients (Zhang, 2012; Liu K. et al., 2020). Some local health

\section{REFERENCES}

Chen, H., He, X., and Wang, J. (2013). Research progress on the clinical effects of Chinese herbal sachets in preventing colds. Chin. J. Ethnomed. Ethnopharm. 22, 45-46.

Ahmad, S., and Beg, Z. H. (2013). Hypolipidemic and antioxidant activities of thymoquinone and limonene in atherogenic suspension fed rats. Food Chem. 138, 1116-1124. doi: 10.1016/j.foodchem.2012.11.109

Backhed, F., Ley, R. E., Sonnenburg, J. L., Peterson, D. A., and Gordon, J.II (2005). Host-bacterial mutualism in the human intestine. Science 307, 1915-1920. doi: $10.1126 /$ science. 1104816

Barter, P. (2005). The inflammation: lipoprotein cycle. Atheroscler Suppl. 6, 15-20. doi: 10.1016/j.atherosclerosissup.2005.02.004

Bi, J. P., Li, P., Xu, X. X., Wang, T., and Li, F. (2018). Anti-rheumatoid arthritic effect of volatile components in notopterygium incisum in rats via anti- committees or Chinese medicine administration bureaus are actively involved in promoting aromatic traditional Chinese medicine as an anti-epidemic, as well as the use of fumigation or Chinese medicine sachet to prevent and control COVID-19 (Chen et al., 2020).

There is no doubt that the pharmacological effects of volatile components of traditional Chinese medicine are beneficial in the global fight against COVID-19. However, each TCM prescription has multiple goals and links in the treatment of diseases, making it difficult to clearly and thoroughly explain its mechanism in a short period. More research should be carried out on volatile components of traditional Chinese medicine to elucidate the associated regulatory mechanism, evaluate possible side effects, and conduct standard clinical trials. The insights provided in this review may help ease the COVID-19 pandemic worldwide.

\section{AUTHOR CONTRIBUTIONS}

Q-wH and JW are the corresponding authors on the study. X-rZ and $\mathrm{T}-\mathrm{nL}$ are first authors and responsible for collecting materials and writing the paper. Y-yR, Y-jZ, and $\mathrm{H}-\mathrm{yL}$ helped in organizing the information and edited the article pictures. All authors contributed to the article and approved the submitted version.

\section{FUNDING}

This work is financially supported by the Xinglin Scholar Talent Promotion Plan of Chengdu University of Traditional Chinese Medicine (QNXZ2018023, XSGG2019008).

\section{ACKNOWLEDGMENTS}

We are indebted to our alma mater, Chengdu University of Traditional Chinese Medicine for provided convenience in the collection of documents. Thanks for all the help from everyone in our lab.

inflammatory and anti-angiogenic activities. Chin. J. Natural Med. 16, $926-$ 935. doi: 10.1016/s1875-5364(18)30134-1

Biondi, J. W., Hines, C.R. L., Barash, P. G., Baker, C. C., Matthay, M. A., and Matthay, R. A. (1986). The acute respiratory distress syndrome. The Yale J. Of Biol. And Med. 59, 575-597.

Bradley, K. C., Finsterbusch, K., Schnepf, D., Crotta, S., Llorian, M., Davidson, S., et al. (2019). Microbiota-Driven Tonic Interferon Signals in Lung Stromal Cells Protect from Influenza Virus Infection. Cell Rep. 28, 245-256 e244. doi: 10.1016/j.celrep.2019.05.105

Brasky, T. M., Baik, C. S., Slatore, C. G., Alvarado, M., and White, E. (2012). Pressssdiagnostic nonsteroidal anti-inflammatory drug use and lung cancer survival in the VITAL study. J. Thorac. Oncol. 7, 1503-1512. doi: 10.1097/ JTO.0b013e3182641bdc

Brotherton, H., Usuf, E., Nadjm, B., Forrest, K., Bojang, K., Samateh, A. L., et al (2020). Dexamethasone for COVID-19: data needed from randomised clinical 
trials in Africa. Lancet Global Health 8 (9), e1125-e1126. doi: 10.1016/s2214$109 x(20) 30318-1$

Cain, D. W., and Cidlowski, J. A. (2017). Immune regulation by glucocorticoids. Nat. Rev. Immunol. 17, 233-247. doi: 10.1038/nri.2017.1

Cani, P. D., and Delzenne, N. M. (2007). Gut microflora as a target for energy and metabolic homeostasis. Curr. Opin. Clin. Nutr. Metab. Care 10, 729- 734. doi: 10.1097/MCO.0b013e3282efdebb

Cao, D., Xu, Z., and Wang, F. (2015). Chemical Composition and Antiinflammatory Effects of Essential Oil from Houpo (Magnolia Officinalis Bark). Chin. J. Trad. Med. Sci. Technol. 22, 647-649.

Cao, P., Zhang, Y., Huang, Z., Sullivan, M. A., He, Z., Wang, J., et al. (2019). The Preventative Effects of Procyanidin on Binge Ethanol-Induced Lipid Accumulation and ROS Overproduction via the Promotion of Hepatic Autophagy. Mol. Nutr. Food Res. 63, e1801255. doi: 10.1002/mnfr.201801255

Cao, B., Wang, Y., Wen, D., Liu, W., Wang, J., Fan, G., et al. (2020). A Trial of Lopinavir-Ritonavir in Adults Hospitalized with Severe Covid-19. N Engl. J. Med. 382, 1787-1799. doi: 10.1056/NEJMoa2001282

Cao, P., Wu, S., Wu, T., Deng, Y., Zhang, Q., Wang, K., et al. (2020). The important role of polysaccharides from a traditional Chinese medicine-Lung Cleansing and Detoxifying Decoction against the COVID-19 pandemic. Carbohydr. Polym. 240:116346. doi: 10.1016/j.carbpol.2020.116346

Castro, M. A., Rodenak-Kladniew, B., Massone, A., Polo, M., Garcia De Bravo, M., and Crespo, R. (2018). Citrus reticulata peel oil inhibits non-small cell lung cancer cell proliferation in culture and implanted in nude mice. Food Funct. 9, 2290-2299. doi: 10.1039/C7FO01912B

Castro, M. A., Llanos, M. A., Rodenak-Kladniew, B. E., Gavernet, L., Galle, M. E., and Crespo, R. (2020). Citrus reticulata peel oil as an antiatherogenic agent: Hypolipogenic effect in hepatic cells, lipid storage decrease in foam cells, and prevention of LDL oxidation. Nutr. Metab. Cardiovasc. Dis. doi: 10.1016/ j.numecd.2020.04.033

Chan, J. F., Chan, K. H., Kao, R. Y., To, K. K., Zheng, B. J., Li, C. P., et al. (2013). Broad-spectrum antivirals for the emerging Middle East respiratory syndrome coronavirus. J. Infect. 67, 606-616. doi: 10.1016/j.jinf.2013.09.029

Chan, J. F., Zhang, A. J., Yuan, S., Poon, V. K., Chan, C. C., Lee, A. C., et al. (2020). Simulation of the clinical and pathological manifestations of Coronavirus Disease 2019 (COVID-19) in golden Syrian hamster model: implications for disease pathogenesis and transmissibility. Clin. Infect. Dis. an Off. Publ. Infect. Dis. Soc. America. doi: 10.1093/cid/ciaa325

Chen, D., and Wang, C. (1994). The quality of Chinese medicine and its rational application (Nanjing: Jiangsu Science and Technology Press).

Chen, F., Chan, K. H., Jiang, Y., Kao, T., Lu, H., Fan, K. W., et al. (2004). In vitro susceptibility of 10 clinical isolates of SARS coronavirus to selected antiviral compounds. J. Clin. Virol. Off. Publ. Pan Am. Soc. Clin. Virol. 31, 69-75. doi: $10.1016 /$ j.jcv.2004.03.003

Chen, H., Liao, H., Liu, Y., Zheng, Y., Wu, X., Su, Z., et al. (2015). Protective effects of pogostone from Pogostemonis Herba against ethanol-induced gastric ulcer in rats. Fitoterapia 100, 110-117. doi: 10.1016/j.fitote.2014.11.017

Chen, X. Y., Dou, Y. X., Luo, D. D., Zhang, Z. B., Li, C. L., Zeng, H. F., et al. (2017). $\beta$-Patchoulene from patchouli oil protects against LPS-induced acute lung injury via suppressing NF- $\mathrm{KB}$ and activating Nrf2 pathways. Int. Immunopharmacol. 50, 270-278. doi: 10.1016/j.intimp.2017.07.001

Chen, C.-Y., Dong, H.-Y., Ji, R.-F., Liu, C.-X., and He, X. (2020). Discussion on role of aromatic Chinese herbs in prevention and treatment of COVID-19 based on theory of traditional Chinese medicine. Chin. Trad. Herbal Drugs 51, 3051-3061.

Cheng, Y., Mai, J. Y., Hou, T. L., Ping, J., and Chen, J. J. (2016). Antiviral activities of atractylon from Atractylodis Rhizoma. Mol. Med. Rep. 14, 3704-3710. doi: $10.3892 / \mathrm{mmr} .2016 .5713$

Chu, S. S., Jiang, G. H., and Liu, Z. L. (2011). Insecticidal compounds from the essential oil of Chinese medicinal herb Atractylodes chinensis. Pest Manage. Sci. 67, 1253-1257. doi: 10.1002/ps.2180

Dai, M., Peng, C., and Sun, F. (2016). Anti-infectious efficacy of essential oil from Caoguo (Fructus Tsaoko). J. Trad. Chin. Med. 36, 799-804. doi: 10.1016/ S0254-6272(17)30018-3

Dang, N. H., Anh, L. V., and Dat, N. T. (2020). Anti-Inflammatory Effects of Essential Oils of Amomum aromaticum Fruits in LipopolysaccharideStimulated RAW264.7 Cells. J. Food Qual. 2020:5. doi: 10.1155/2020/8831187
Dias, A. L. B., Sousa, W. C., Batista, H. R. F., Alves, C. C. F., Souchie, E. L., Silva, F. G., et al. (2020). Chemical composition and in vitro inhibitory effects of essential oils from fruit peel of three Citrus species and limonene on mycelial growth of Sclerotinia sclerotiorum. Braz. J. Biol. 80, 460-464. doi: 10.1590/15196984.216848

Durham, A. L., and Adcock, I. M. (2015). The relationship between COPD and lung cancer. Lung Cancer 90, 121-127. doi: 10.1016/j.lungcan.2015.08.017

El-Ghorab, A. H., Nauman, M., Anjum, F. M., Hussain, S., and Nadeem, M. (2010). A comparative study on chemical composition and antioxidant activity of ginger (Zingiber officinale) and cumin (Cuminum cyminum). J. Agric. Food Chem. 58, 8231-8237. doi: 10.1021/jf101202x

Fischer, J., and Dethlefsen, U. (2013). Efficacy of cineole in patients suffering from acute bronchitis: a placebo-controlled double-blind trial. Cough (London Engl). 9:25. doi: 10.1186/1745-9974-9-25

Flume, P. A., O'sullivan, B. P., Robinson, K. A., Goss, C. H., Mogayzel, P. J.Jr., Willey-Courand, D. B., et al. (2007). Cystic fibrosis pulmonary guidelines: chronic medications for maintenance of lung health. Am. J. Respir. Crit. Care Med. 176, 957-969. doi: 10.1164/rccm.200705-664OC

Gill, S. R., Pop, M., Deboy, R. T., Eckburg, P. B., Turnbaugh, P. J., Samuel, B. S., et al. (2006). Metagenomic analysis of the human distal gut microbiome. Science 312, 1355-1359. doi: 10.1126/science.1124234

Guan, W.-J., Zheng, X.-Y., Chung Kian, F., and Zhong, N.-S. (2016). Impact of air pollution on the burden of chronic respiratory diseases in China: time for urgent action. Lancet 388, 1939-1951. doi: 10.1016/s0140-6736(16)31597-5

Guo, Y., Sha, M., Meng, X., and Cao, A. (2005). The Anti-viral Studies of Notopterygium incisum. Lishizhen Med. Mat. Med. Res. 20 (3), 198-199.

Guo, F., Huang, L., Liang, Y., Zhou, S., and Li, Y. (2008). Headspace Solid-Phase Microextraction-Gas Chromatography-Mass Spectrometry for the Analysis of Volatile Compounds from A.lancea. Natural Prod. Res. Dev., 452-457.

Guo, J. (2012). Research about Effective Ingredients of Magnolia Officinalis Based on Their Antioxidant Activity. [PhD] (Shanghai: East China University of Science and Technology).

Han, N. R., Moon, P. D., Nam, S. Y., Ryu, K. J., Yoou, M. S., Choi, J. H., et al. (2016). Inhibitory effects of atractylone on mast cell-mediated allergic reactions. Chemico-biol. Interact. 258, 59-68. doi: 10.1016/j.cbi.2016.08.015

He, F., Wang, W., Wu, M., Fang, Y., Wang, S., Yang, Y., et al. (2020). Antioxidant and antibacterial activities of essential oil from Atractylodes lancea rhizomes. Ind. Crops Prod. 153, 112552. doi: 10.1016/j.indcrop.2020.112552

Hemila, H. (2017). Vitamin C and Infections. Nutrients 9 (4), 339. doi: 10.3390/ nu9040339

Houdkova, M., Rondevaldova, J., Doskocil, I., and Kokoska, L. (2017). Evaluation of antibacterial potential and toxicity of plant volatile compounds using new broth microdilution volatilization method and modified MTT assay. Fitoterapia 118, 56-62. doi: 10.1016/j.fitote.2017.02.008

Houghton, A. M. (2013). Mechanistic links between COPD and lung cancer. Nat. Rev. Cancer 13, 233-245. doi: 10.1038/nrc3477

Hsieh, C. F., Lo, C. W., Liu, C. H., Lin, S., Yen, H. R., Lin, T. Y., et al. (2012). Mechanism by which ma-xing-shi-gan-tang inhibits the entry of influenza virus. J. Ethnopharmacol. 143, 57-67. doi: 10.1016/j.jep.2012.05.061

Hsu, D. Z., Li, Y. H., Chu, P. Y., Chien, S. P., Chuang, Y. C., and Liu, M. Y. (2006). Attenuation of endotoxin-induced oxidative stress and multiple organ injury by 3,4-Methylenedioxyphenol in rats. Shock 25, 300-305. doi: 10.1097/ 01.shk.0000194719.82845.39

Hu, K., Wei, Y., and An, C. (2010). Application of aromatic herb in external therapy. China J. Trad. Chin. Med. Pharm. 25, 337-339.

Huang, R. T., Wu, D., Meliton, A., Oh, M. J., Krause, M., Lloyd, J. A., et al. (2017). Experimental Lung Injury Reduces Krüppel-like Factor 2 to Increase Endothelial Permeability via Regulation of RAPGEF3-Rac1 Signaling. Am. J. Respir. Crit. Care Med. 195, 639-651. doi: 10.1164/rccm.201604-0668OC

Huang, C., Wang, Y., Li, X., Ren, L., Zhao, J., Hu, Y., et al. (2020). Clinical features of patients infected with 2019 novel coronavirus in Wuhan, China. Lancet 395, 497-506. doi: 10.1016/s0140-6736(20)30183-5

Hung, I. F.-N., Lung, K.-C., Tso, E. Y.-K., Liu, R., Chung, T. W.-H., Chu, M.-Y., et al. (2020). Triple combination of interferon beta- $1 \mathrm{~b}$, lopinavir-ritonavir, and ribavirin in the treatment of patients admitted to hospital with COVID-19: an open-label, randomised, phase 2 trial. Lancet 395, 1695-1704. doi: 10.1016/s0140-6736(20) $31042-4$ 
Jing, L., Lei, Z., Zhang, G., Pilon, A. C., Huhman, D. V., Xie, R., et al. (2015). Metabolite profiles of essential oils in citrus peels and their taxonomic implications. Metabolomics 11, 952-963. doi: 10.1007/s11306-014-0751-x

Johns Hopkins University \& Medicine, J.H.U (2020). COVID-19 Dashboard by the Center for Systems Science and Engineering (CSSE) at Johns Hopkins University (JHU). Available at: https://coronavirus.jhu.edu/map.html (Accessed 18th August 2020).

Juergens, U. R., Stöber, M., and Vetter, H. (1998a). Inhibition of cytokine production and arachidonic acid metabolism by eucalyptol (1.8-cineole) in human blood monocytes in vitro. Eur. J. Med. Res. 3, 508-510.

Juergens, U. R., Stöber, M., Schmidt-Schilling, L., Kleuver, T., and Vetter, H. (1998b). Antiinflammatory effects of euclyptol (1.8-cineole) in bronchial asthma: inhibition of arachidonic acid metabolism in human blood monocytes ex vivo. Eur. J. Med. Res. 3, 407-412.

Kanako, S., Fumiko, N., and Itsu, K. (2000). Inhibition of H+,K+-ATPase by hinesol, a major component of So-jutsu, by interaction with enzyme in the E1 state. Biochem. Pharmacol. 59, 881-886. doi: 10.1016/S0006-2952(99)00399-8

Kennedy-Feitosa, T. E., Okuro, R. V., Pinho Ribeiro, M., Lanzetti, V., Barroso, M. A., Zin, W., et al. (2016). Eucalyptol attenuates cigarette smoke-induced acute lung inflammation and oxidative stress in the mouse. Pulmonary Pharmacol. Ther. 41, 11-18. doi: 10.1016/j.pupt.2016.09.004

Kim, D. S., Lee, H. J., Jeon, Y. D., Han, Y. H., Kee, J. Y., Kim, H. J., et al. (2015). Alpha-Pinene Exhibits Anti-Inflammatory Activity Through the Suppression of MAPKs and the NF- $\kappa B$ Pathway in Mouse Peritoneal Macrophages. Am. J. Chin. Med. 43, 731-742. doi: 10.1142/s0192415x15500457

Kim, H. Y., Nam, S. Y., Hwang, S. Y., Kim, H. M., and Jeong, H. J. (2016). Atractylone, an active constituent of KMP6, attenuates allergic inflammation on allergic rhinitis in vitro and in vivo models. Mol. Immunol. 78, 121-132. doi: 10.1016/j.molimm.2016.09.007

Konstan, M. W., Wagener, J. S., Pasta, D. J., Millar, S. J., Jacobs, J. R., Yegin, A., et al. (2011). Clinical use of dornase alpha is associated with a slower rate of FEV1 decline in cystic fibrosis. Pediatr. Pulmonol. 46, 545-553. doi: 10.1002/ ppul. 21388

Kruk, J., Aboul-Enein, H. Y., Kladna, A., and Bowser, J. E. (2019). Oxidative stress in biological systems and its relation with pathophysiological functions: the effect of physical activity on cellular redox homeostasis. Free Radic. Res. 53, 497-521. doi: 10.1080/10715762.2019.1612059

Kun, L., Hongxia, L., and Mingyu, D. (2000). Analysis of tetramethylpyrazine in Ephedrae herba by gas chromatography-mass spectrometry and highperformance liquid chromatography. J. Chromatogr. A. 878, 147-152. doi: 10.1016/S0021-9673(00)00248-X

Lester, M., Sahin, A., and Pasyar, A. (2020). The use of dexamethasone in the treatment of COVID-19. Ann. Med. Surg. (Lond). 56, 218-219. doi: 10.1016/ j.amsu.2020.07.004

Li, L.-C., and Kan, L.-D. (2017). Traditional Chinese medicine for pulmonary fibrosis therapy: Progress and future prospects. J. Ethnopharmacol. 198, 45-63. doi: 10.1016/j.jep.2016.12.042

Li, Y. C., Xian, Y. F., Su, Z. R., Ip, S. P., Xie, J. H., Liao, J. B., et al. (2014). Pogostone suppresses proinflammatory mediator production and protects against endotoxic shock in mice. J. Ethnopharmacol. 157, 212-221. doi: 10.1016/ j.jep.2014.09.023

Li, Y., Lai, Y., Wang, Y., Liu, N., Zhang, F., and Xu, P. (2016). 1, 8-Cineol Protect Against Influenza-Virus-Induced Pneumonia in Mice. Inflammation 39, 15821593. doi: $10.1007 /$ s10753-016-0394-3

Li, D., Chen, Y., Li, Y., and Fang, J. (2020). Two Cases of COVID-19 Treated Effectively with Modified Da Yuan Drinking. Jiangsu J. Trad. Chin. Med. 52, 59-61.

Li, H., Shen, L., and Wang, N. (2020). Review of Classical Famous Prescription "Dayuanyin" Used for the Treatment of COVID-19 and Analysis of Pulmonary Classical Famous Prescriptions. China Invent. Patent. 17, 40-49.

Lian, P., Xia, Y., and Wei, R. (2020). Discussion on TCM Theories of "Qingwen Pihui San" to Prevent New Coronavirus Pneumonia. J. GuiZhou Univ. Trad. Chin. Med. 42, 18-21.

Lim, H. P., Emberson, W. S., Mafham, J., Bell, M., Linsell, J., Staplin, L., et al. Effect of Dexamethasone in Hospitalized Patients with COVID-19 - Preliminary Report. MedRxiv. doi: 10.1101/2020.06.22.20137273

Lin, P. C., Lee, J. J., and Chang, I. J. (2016). Essential oils from Taiwan: Chemical composition and antibacterial activity against Escherichia coli. J. Food Drug Anal. 24, 464-470. doi: 10.1016/j.jfda.2015.12.006
Lin, S.-H., Zhao, Y.-S., Zhou, D.-X., Zhou, F.-C., and Xu, F. (2020). Coronavirus Disease 2019 (COVID-19): Cytokine Storms, Hyper-Inflammatory Phenotypes, and Acute Respiratory Distress Syndrome. Genes Dis. doi: 10.1016/j.gendis.2020.06.009

Liu, C.-X., Wang, Y.-L., Zhang, H.-B., Tian, C.-W., Huang, H., and Zhang, T.-J. (2020). Attach importance to research and development of Chinese materia medica based on prevention and control needs of SARS-CoV-2 infection. Chin. Trad. Herb. Drugs. 51, 1361-1374. doi: 10.7501/j.issn.0253-2670.2020.06.001

Liu, K., Guan, D., Li, L., Ni, H., and Chen, L. (2020). Feasibility Analysis of Moxibustion Whole Process Intervention in the Prevention and Treatment of COVID-19. Acta Chin. Med. 35, 1144-1147.

Lubamba, B., Panin, N., Lebacq, J., Huaux, F., Lebecque, P., Wallemacq, P., et al. (2011). 70 Vardenafil as anti-inflammatory drug in the treatment of cystic fibrosis lung disease. J. Cystic Fibrosis 10, S18. doi: 10.1016/s1569-1993(11) 60088-x

Lun, X., and Chen, X. (1987). Prevention and treatment of aromatic Chinese medicine. Chin. Trad. Patent Med. 198, 45-63.

Luo, J., Yin, N., Huang, X.-Y., Zhang, H., Li, H.-T., Ren, G.-L., et al. (2020). Study on the Mechanism of Aromatic Traditional Chinese Medicine Compound on Prevention and Treatment of New Coronavirus Pneumonia. J. Jiangxi Univ. Trad. Chin. Med. 32, 66-73.

Lvy, P., and Bai, M. (2017). Discussion on the effect of air disinfection for aromatic smell of traditional Chinese medicine Sachet. Strait Pharm. J. 29, 47-48.

Macintyre, C. R., Chughtai, A. A., Barnes, M., Ridda, I., Seale, H., Toms, R., et al. (2018). The role of pneumonia and secondary bacterial infection in fatal and serious outcomes of pandemic influenza a(H1N1)pdm09. BMC Infect. Dis. 18, 637. doi: 10.1186/s12879-018-3548-0

Marinho, P. M., Marcos, A. A. A., Romano, A. C., Nascimento, H., and Rubens, B. Jr. (2020). Retinal findings in patients with COVID-19. Lancet 395 (10237), 1610. doi: 10.1016/S0140-6736(20)31014-X

Mesomo, M. C., Corazza, M. L., Ndiaye, P. M., Dalla Santa, O. R., Cardozo, L., and Scheer, A. D. (2013). Supercritical CO2 extracts and essential oil of ginger (Zingiber officinale R.): Chemical composition and antibacterial activity. J. Supercritical Fluids 80, 44-49. doi: 10.1016/j.supflu.2013.03.031

Mitsui, S., Torii, K., Fukui, H., Tsujimura, K., Maeda, A., Nose, M., et al. (2010). The herbal medicine compound falcarindiol from Notopterygii Rhizoma suppresses dendritic cell maturation. J. Pharmacol. Exp. Ther. 333, 954-960. doi: 10.1124/jpet.109.162305

Mittal, M., Siddiqui, M. R., Tran, K., Reddy, S. P., and Malik, A. B. (2014). Reactive oxygen species in inflammation and tissue injury. Antioxida Redox Signal. 20, 1126-1167. doi: 10.1089/ars.2012.5149

Müller, J., Greiner, J. F., Zeuner, M., Brotzmann, V., Schäfermann, J., Wieters, F., et al. (2016). 1,8-Cineole potentiates IRF3-mediated antiviral response in human stem cells and in an ex vivo model of rhinosinusitis. Clin. Sci. (London Engl. 1979). 130, 1339-1352. doi: 10.1042/cs20160218

Naderi, G. A., Asgary, S., Ani, M., Sarraf-Zadegan, N., and Safari, M. R. (2004). Effect of some volatile oils on the affinity of intact and oxidized lowdensity lipoproteins for adrenal cell surface receptors. Mol. Cell. Biochem. 267, 59-66. doi: 10.1023/B:MCBI.0000049365.60694.81

National., General Office of China., Health Commission of the People's Republic Of and Medicine., Office of State Administration of Traditional Chinese (2020). Diagnosis and treatment of corona virus disease-19(7th trial edition). China Med. 15, 801-805.

Nutman, T. B. (2020). Human infection with Strongyloides stercoralis and other related Strongyloides species. Parasitology 144 (3), 263-273. doi: 10.1017/ S0031182016000834

Oriol, M., and Bonaventura, C. (2020). Use of antiviral drugs to reduce COVID-19 transmission. Lancet Global Health 8, e639-e640. doi: 10.1016/s2214-109x(20) 30114-5

Pan, P.-P., Sun, K.-P., Zheng, Y.-P., Jin, J.-J., and Shu-Pei, L. (2020). Qualitative Study on Volatile Components of Different Reticulatae Pericarpium Products Based on GC-MS. Modern Chin. Med. doi: 10.13313/j.issn.1673-4890.20190917001

Pan, X., Dong, L., Yang, L., Chen, D., and Peng, C. (2020). Potential drugs for the treatment of the novel coronavirus pneumonia (COVID-19) in China. Virus Res. 286, 198057. doi: 10.1016/j.virusres.2020.198057

Podlogar, J. A., and Verspohl, E. J. (2012). Antiinflammatory effects of ginger and some of its components in human bronchial epithelial (BEAS-2B) cells. Phytother Res. PTR 26, 333-336. doi: 10.1002/ptr.3558 
Qian, Y. (2019). Effect of Shufeng Jiedu Capsule on Serum PGE2, IL-1 $\beta$ and TNF- $\alpha$ in Rats with Acute Pharyngitis and Clinical Efficacy Observation. [master's thesis] (Hefei: Anhui University of Chinese Medicine).

Rabe, K. F., and Watz, H. (2017). Chronic obstructive pulmonary disease. Lancet 389, 1931-1940. doi: 10.1016/s0140-6736(17)31222-9

Ren, J. L., Zhang, A. H., and Wang, X. J. (2020). Traditional Chinese medicine for COVID-19 treatment. Pharmacol. Res. 155, 104743. doi: 10.1016/ j.phrs.2020.104743

Riad, N., Zahi, M. R., Trovato, E., Bouzidi, N., Daghbouche, Y., Utczás, M., et al. (2020). Chemical screening and antibacterial activity of essential oil and volatile fraction of Dictyopteris polypodioides. Microchem. J. 152, 104415. doi: 10.1016/j.microc.2019.104415

Ruan, X., Du, P., Zhao, K., Huang, J., Xia, H., Dai, D., et al. (2020). Mechanism of Dayuanyin in the treatment of coronavirus disease 2019 based on network pharmacology and molecular docking. Chin Med. 15, 62. doi: 10.1186/s13020020-00346-6

Schuijt, T. J., Lankelma, J. M., Scicluna, B. P., De Sousa E Melo, F., Roelofs, J. J., De Boer, J. D., et al. (2016). The gut microbiota plays a protective role in the host defence against pneumococcal pneumonia. Gut 65, 575-583. doi: 10.1136/ gutjnl-2015-309728

Schürmann, M., Oppel, F., Gottschalk, M., Büker, B., Jantos, C. A., Knabbe, C., et al. (2019). The Therapeutic Effect of 1,8-Cineol on Pathogenic Bacteria Species Present in Chronic Rhinosinusitis. Front. Microbiol. 10, 2325. doi: 10.3389/fmicb.2019.02325

Sies, H. (2015). Oxidative stress: a concept in redox biology and medicine. Redox Biol. 4, 180-183. doi: 10.1016/j.redox.2015.01.002

Silva-Filho, S. E., Wiirzler, L. A. M., Cavalcante, H. A. O., Uchida, N. S., De Souza Silva-Comar, F. M., Cardia, G. F. E., et al. (2016). Effect of patchouli (Pogostemon cablin) essential oil on in vitro and in vivo leukocytes behavior in acute inflammatory response. Biomed. Pharmacother. = Biomed. Pharmacother. 84, 1697-1704. doi: 10.1016/j.biopha.2016.10.084

Stebbing, J., Phelan, A., Griffin, IIIvan, Tucker, C., Oechsle, O., Smith, D., et al. (2020). COVID-19: combining antiviral and anti-inflammatory treatments. Lancet Infect. Dis. 20, 400-402. doi: 10.1016/s1473-3099(20)30132-8

Su, J. Y., Luo, X., Zhang, X. J., Deng, X. L., Su, Z. R., Zhou, L., et al. (2015). Immunosuppressive activity of pogostone on $\mathrm{T}$ cells: Blocking proliferation via $\mathrm{S}$ phase arrest. Int. Immunopharmacol. 26, 328-337. doi: 10.1016/j.intimp.2015.04.019

Sudhoff, H., Klenke, C., Greiner, J., Müller, J., Brotzmann, V., Ebmeyer, J., et al. (2015). 1,8-Cineol Reduces Mucus-Production in a Novel Human Ex Vivo Model of Late Rhinosinusitis. PloS One 10, e0133040. doi: 10.1371/ journal.pone. 0133040

Sun, L.-Z., and Liang, J. (2015). Modern enlightenment on aromatic drugs in the prevention and treatment of epidemic diseases in Ming and Qing dynasties. China J. Trad. Chin. Med. Pharm. 30, 4407-4409.

Sun, C. Y., Xu, L. Q., Zhang, Z. B., Chen, C. H., Huang, Y. Z., Su, Z. Q., et al. (2016). Protective effects of pogostone against LPS-induced acute lung injury in mice via regulation of Keap $1-\mathrm{Nrf} 2 / \mathrm{NF}-\mathrm{\kappa B}$ signaling pathways. Int. Immunopharmacol. 32, 55-61. doi: 10.1016/j.intimp.2016.01.007

Tang, F., Fan, K., Wang, K., and Bian, C. (2018). Atractylodin attenuates lipopolysaccharide-induced acute lung injury by inhibiting NLRP3 inflammasome and TLR4 pathways. J. Pharmacol. Sci. 136, 203-211. doi: 10.1016/j.jphs.2017.11.010

Tang, F., Liu, M., Zhang, S., Wang, J., Sheng, Y., Feng, W., et al. (2019). Comparative Study on Chemical Composition and Antibacterial Activity of Essential Oils from Patchouli and Magnolia officinalis Alone and Combination. Trad. Chin. Drug Res. Clin. Pharmacol. 30, 478-483.

Trial, Recovery (Randomised Evaluation of Covid-19 Therapy) (2020). Low-cost dexamethasone reduces death by up to one third in hospitalised patients with severe respiratory complications of COVID-19. Available at: https://www. recoverytrial.net (Accessed 13th, Aug, 2020).

Vieira, A. J., Beserra, F. P., Souza, M. C., Totti, B. M., and Rozza, A. L. (2018). Limonene: Aroma of innovation in health and disease. Chem. Biol. Interact. 283, 97-106. doi: 10.1016/j.cbi.2018.02.007

Vogelmeier, C., Buhl, R., Burghuber, O., Criée, C. P., Ewig, S., Godnic-Cvar, J., et al. (2018). [Guideline for the Diagnosis and Treatment of COPD Patients Issued by the German Respiratory Society and the German Atemwegsliga in Cooperation with the Austrian Society of Pneumology]. Pneumologie (Stuttgart Germany) 72, 253-308. doi: 10.1055/s-0043-125031
Wang, B., Xu, B., Fan, Y.-L., Li, B., Cong, X.-D., Dong, G.-J., et al. (2020) Experience in Treatment of COVID-19 by Elimination of Pathogens Through Purgation and Diuresis. Chin. J. Exp. Trad. Med. Formulae 6 (19), 53-59.

Wang, J., Xue, B., Liang, A., Wang, L., Fu, M., and Ye, Z. (2002). Effects of $\beta$ eudesmol, an active constituent from Rhizoma Atractylodis on small intestine movement in rats. Chin. Pharm. J., 28-30.

Wang, X.-Y., Chen, Y.-Y., and Bao, J.-K. (2018). Study on the molecular mechanism of pogotone against Staphylococcus aureus. Chin. J. Antibiotics 43, 759-764.

Wang, W., Chen, Y., and Qing, W. (2020). "A case of Dayuan Yin and LiuJunZi Decoction Treating with COVID-19," in National Conference on Scientific Research Theory and Academic Research. Beijing, China: China Global Culture Publishing Hous.

Wei, X., Peng, C., and Wan, F. (2012). Study on the effect of anti-respiratory viruses of Patchouli Oil in vitro. Pharmacol. Clinics Chin. Mat. Medica. 28, 65-68.

Welliver, R., Monto, A. S., Carewicz, O., Schatteman, E., Hassman, M., Hedrick, J., et al. (2001). Effectiveness of oseltamivir in preventing influenza in household contacts: a randomized controlled trial. JAMA 285, 748-754. doi: 10.1001/jama.285.6.748

Wilson, D. O., Weissfeld, J. L., Fuhrman, C. R., Fisher, S. N., Balogh, P., Landreneau, R. J., et al. (2008). The Pittsburgh Lung Screening Study (PLuSS): outcomes within 3 years of a first computed tomography scan. Am. J. Respir. Crit. Care Med. 178, 956-961. doi: 10.1164/rccm.200802-336OC

Worth, H., and Dethlefsen, U. (2012). Patients with asthma benefit from concomitant therapy with cineole: a placebo-controlled, double-blind trial. J. asthma Off. J. Assoc. Care Asthma 49, 849-853. doi: 10.3109/02770903.2012.717657

Worth, H., Schacher, C., and Dethlefsen, U. (2009). Concomitant therapy with Cineole (Eucalyptole) reduces exacerbations in COPD: a placebo-controlled double-blind trial. Respir. Res. 10:69. doi: 10.1186/1465-9921-10-69

Wu, S. B., Zhao, Y., Fan, H., Hu, Y. H., Hamann, M. T., Peng, J. N., et al. (2008). New guaiane sesquiterpenes and furanocoumarins from Notopterygium incisum. Planta Med. 74, 1812-1817. doi: 10.1055/s-0028-1088326

Wu, F., Zhao, S., Yu, B., Chen, Y. M., Wang, W., Song, Z. G., et al. (2020). A new coronavirus associated with human respiratory disease in China. Nature 579, 265-269. doi: 10.1038/s41586-020-2008-3

Xiong, J., and Hua, E. (2012). Orthogonal Array Design for the Optimization of Supercritical $\mathrm{CO}_{2}$ Extraction of Volatile Oil from Amomum tsaoko Fruits. Food Sci. 33, 48-51.

Xu, J., Li, Y., Zhai, J., Li, Y., Zhang, L., and Zhang, G. (2016). Theoretical Origin and Practical Thinking of the Theory of Chinese Medicine Preventive Treatment of Disease. J. Trad. Chin. Med. 57, 1351-1354.

Xue, J., Wang, L., Liu, L., and Chai, H. (2020). Analysis of Volatile Components of Ephedra from Different Places Based on GC-MS. J. Chin. Medi. Mater., 359-362.

Yang, Y., Yang, Y., Yan, R., and Zou, G. (2010). Cytotoxic, apoptotic and antioxidant activity of the essential oil of Amomum tsao-ko. Bioresource Technol. 101, 4205-4211. doi: 10.1016/j.biortech.2009.12.131

Yang, H. M., Zhuo, J. Y., Sun, C. Y., Nie, J., Yuan, J., Liu, Y. L., et al. (2018). Pogostone attenuates TNF- $\alpha$-induced injury in A549 cells via inhibiting NF$\kappa \mathrm{B}$ and activating $\mathrm{Nrf2}$ pathways. Int. Immunopharmacol. 62, 15-22. doi: 10.1016/j.intimp.2018.06.029

Yao, F., Liu, W., and Qiu, Q. (2001). GC-MS Analysis of Volatile Oil from Atractylodes chinensis. J. Chin. Medi. Mater. 24 (9), 643-645.

Yao, X. H., Li, T. Y., He, Z. C., Ping, Y. F., Liu, H. W., Yu, S. C., et al. (2020). A pathological report of three COVID-19 cases by minimal invasive autopsies. Zhonghua bing li xue za zhi = Chin. J. Pathol. 49, 411-417. doi: 10.3760/ cma.j.cn112151-20200312-00193

Yoon, W.-J., Lee, N. H., and Hyun, C.-G. (2010). Limonene suppresses lipopolysaccharide-induced production of nitric oxide, prostaglandin E2, and pro-inflammatory cytokines in RAW 264.7 macrophages. J. Oleo Sci. 59, 415421. doi: $10.5650 /$ jos.59.415

Zhang, H., Chen, Q., Zhou, W., Gao, S., Lin, H., Ye, S., et al. (2013). Chinese medicine injection shuanghuanglian for treatment of acute upper respiratory tract infection: a systematic review of randomized controlled trials. Evid. Based Complement Alternat. Med. 2013:987326. doi: 10.1155/2013/987326

Zhang, Q., Wang, H., Ma, L., Tan, J., and Chen, M. (2014). Effect of Miao medicine Fanggan sachet on expression of NKp46 in peripheral blood of mice. Guangdong Med. J. 35, 1320-1322.

Zhang, T. T., Lu, C. L., and Jiang, J. G. (2014). Bioactivity evaluation of ingredients identified from the fruits of Amomum tsaoko Crevost et Lemaire, a Chinese spice. Food Funct. 5, 1747-1754. doi: 10.1039/c4fo00169a 
Zhang, P., Wu, Q., Chen, L., and Duan, K. (2020). Pseudomonas aeruginosaVirulence-Inhibiting Herbal Compound Falcarindiol Significantly Reduced Mortality in Mice Infected with. Antibiotics (Basel Switzerland) 9 (3), 136. doi: 10.3390/antibiotics 9030136

Zhang, X. (2012). The antibacterial effect of Cangzhu and its application in the disinfection of hospital environment. China Foreign Med. Treat. 31, 184-185.

Zhao, C., Sun, J., Fang, C., and Tang, F. (2014). 1,8-cineol attenuates LPS-induced acute pulmonary inflammation in mice. Inflammation 37, 566-572. doi: 10.1007/s10753-013-9770-4

Zhou, J. Y., Tang, F. D., Mao, G. G., and Bian, R. L. (2004). Effect of alpha-pinene on nuclear translocation of NF-kappa B in THP-1 cells. Acta Pharmacol. Sinica 25, 480-484

Zhou, Y., Peng, C., Wang, F., and Cao, X. (2014). Effect of patchouli oil on acute bacterial upper respiratory infections model mice. Pharmacol. Clinics Chin. Mat. Medica. 30, 59-62.
Zhu, X., Wang, B., Zhang, X., Chen, X., Zhu, J., Zou, Y., et al. (2020). Alphalinolenic acid protects against lipopolysaccharide-induced acute lung injury through anti-inflammatory and anti-oxidative pathways. Microb. Pathog. 142, 104077. doi: 10.1016/j.micpath.2020.104077

Conflict of Interest: The authors declare that the research was conducted in the absence of any commercial or financial relationships that could be construed as a potential conflict of interest.

Copyright (C) 2020 Zhang, Li, Ren, Zeng, Lv, Wang and Huang. This is an open-access article distributed under the terms of the Creative Commons Attribution License (CC BY). The use, distribution or reproduction in other forums is permitted, provided the original author(s) and the copyright owner(s) are credited and that the original publication in this journal is cited, in accordance with accepted academic practice. No use, distribution or reproduction is permitted which does not comply with these terms. 